\section{Surgical Review: International Journal of Surgery Trauma and Orthopedics}

2020 Volume 6 Number 4 July-August

\title{
A study on the diagnostic approach to palpable breast lump through a modified triple assessment
}

\author{
G Devi R. ${ }^{1}$, Sailaja K. ${ }^{2 *}$ \\ DOI: https://doi.org/10.17511/ijoso.2020.i04.12
}

\footnotetext{
${ }^{1}$ Rajani G Devi, Assistant Professor, Department of General Surgery, Rangaraya Medical College, Kakinada, Andhra Pradesh, India.

2* Kallakuri Sailaja, Associate Professor, Department of General Surgery, Rangaraya Medical College, Kakinada, Andhra Pradesh, India.
}

Introduction: Breast cancer is the second most common malignancy among women. With this, a study was conducted to find the sensitivity, specificity, positive predictive value, negative predictive value for the modified triple test (MTT) used in the diagnosis of palpable breast lumps. Materials and Methods: It was a cross sectional study, conducted in the department of General surgery, Rangaraya Medical College. Female aged $>30$ years, complaining about breast lump were included in the study. Breast imaging techniques and cytopathological tests were used for the diagnosis of MTT. The data were analyzed using Microsoft Excel and SPSS software version 22.0. $P<0.05$ was considered statistically significant. Results: A total of 65 participants were included, the mean age was $41.84 \pm 9.1$ years and $62 \%$ were benign. Age-wise, more $(37 \%)$ benign cases in $31-40$ years group and more $(14 \%)$ malignant cases in $51-60$ years group. The left side presentation was predominant $(63 \%)$. Totally $12.3 \%$ (8) women were nulliparous, out of which 2 had malignant lesions and the rest $(57 ; 81.7 \%)$ were multiparous. Statistically, there was no significant difference $(P>0.05)$. Conclusion: Among the three components of this triple assessment, the cytopathological diagnosis was considered to be the most reliable component especially in doubtful cases.

Keywords: Breast, Lump, Report, Study

Corresponding Author

Kallakuri Sailaja, Associate Professor, Department of General Surgery, Rangaraya Medical College, Kakinada, Andhra Pradesh, India. Email: sailaja7074@gmail.com
How to Cite this Article

To Browse

Devi RG, Sailaja K. A study on the diagnostic approach to palpable breast lump through a modified triple assessment. Surgical Rev Int J Surg Trauma Orthoped. 2020;6(4):276-281.

Available From

https://surgical.medresearch.in/index.php/ijoso/artic le/view/174

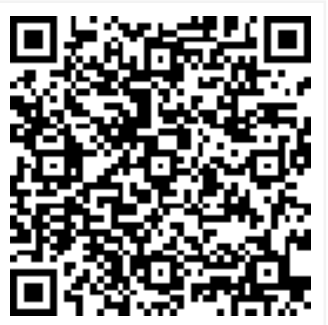

Manuscript Received 2020-04-01

Conflict of Interest No

Review Round 1
2020-05-12
Funding
Nil

Review Round 1

Nil

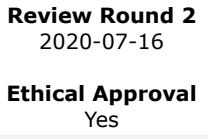

Ethical Approval Yes

Review Round 3

Plagiarism X-checker $8 \%$
Accepted 2020-08-26

(c) 2020 by Rajani G Devi, Kallakuri Sailaja and Published by Siddharth Health Research and Social Welfare Society. This is an Open Access article licensed under a Creative Commons Attribution 4.0 International License https://creativecommons.org/licenses/by/4.0/ unported [CC BY 4.0]. 


\section{Introduction}

In India breast cancer is the second most common malignancy among women [1], breast lump is the most common clinical presentation in majority of the breast diseases. Most of the breast diseases are benign [2]. However, there is an apprehension in the minds of patients that the lump may be malignant.

Over the years there has been a considerable increase in the incidence of breast diseases. With increasing public and professional awareness, each year a large number of women with palpable breast masses are being referred to surgeons. In order to reduce this anxiety among women, the surgeons have a sympathetic approach with the patient.

The majority of them prove to be benign, but the probability of the diagnosis of cancer is never zero. So careful examination, exact diagnosis, and definite treatment are mandatory in any breast mass $[3,4]$. Moreover, every palpable mass in the breast must be assessed and clarified [5].

The triple test was first described by Johansen in 1970, for the evaluation of palpable breast masses by physical examination, mammography, and fineneedle aspiration cytology [6]. Hermansen et al. bring this into clinical practice in 1987 [7]. Due to the limitation of mammography, a modified triple test (MTT) was introduced by Vetto et al. In the MTT, the ultrasonogram is replaced by mammography.

Utility in women $<35$ years due to dense breast parenchyma and avoiding radiation exposure are the advantages of MTT [9]. Subsequent histopathology was found to correlate well with the preoperative diagnosis using triple assessment. The palpable lump can be diagnosed as malignant with this multi assessment $[8,10,11]$.

With these, a study was conducted to find the sensitivity, specificity, positive predictive value (PPV), negative predictive value (NNV) for MTT used in the diagnosis of palpable breast lumps.

\section{Materials and Methods}

Settings: It was a cross-sectional study, conducted in the department of General surgery, Rangaraya Medical College, Kakinada.

Duration of study: The study was conducted from July 2014 to August 2016.
Sampling method: Random sampling was considered in this study.

Inclusion criteria: Female aged $>30$ years, complaining about breast lump were included in the study.

Exclusion criteria: Male breast cancer, individuals with fungating mass or advanced malignancy of breast, individuals $\leq 18$ years, and who didn't submit the informed written consent were excluded from the study.

Sample size: All the individuals who satisfy the inclusion criteria during the study period were included in the study.

Ethical approval: The study protocol was approved by the institutional ethical committee.

Breast disease was diagnosed using criteria given by Townsend Jr C et al. [12]. During history taking, the previous history of breast biopsies, hysterectomy, the recent history of pregnancy and lactation, hormonal usage for contraception, and family history were recorded. With respect to the specific breast complaint, the information in the form of history of mass, breast pain, nipple discharge, and any skin changes. The presence of mass and changes in the menstrual cycle were also recorded.

Careful physical examination of the study participants in the upright sitting position for obvious masses, asymmetries, and skin changes was also recorded. This was followed by palpation of the breast tissue and to find the enlarged axillary lymph nodes.

Breast imaging techniques were used to detect small, non-palpable breast abnormalities [13] and ultrasonography (USG) to determine breast mass was a cyst or solid lesion [14]. The cytopathological diagnosis was done using fine-needle aspiration cytology (FNAC) and reported as per the standard guidelines $[16,17]$.

The data were analyzed using Microsoft Excel and SPSS software version 22.0. Descriptive statistics such as percentage, mean, median were used. $\mathrm{P}<0.05$ was considered statistically significant.

\section{Results}

A total of 65 participants were included in the study, the mean age was $41.84 \pm 9.1$ years. The mean age among the patients with malignancy was 47 years, ranging between 30 to 65 years. 
Table-1: Age-wise distribution Incidence of breast lumps.

\begin{tabular}{|l|l|l|}
\hline \multicolumn{1}{|c|}{ Age } & \multicolumn{1}{c|}{ Number } & \multicolumn{1}{c|}{ Percentage } \\
\hline $31-40$ & 28 & 43.77 \\
\hline $41-50$ & 15 & 23.07 \\
\hline $51-60$ & 13 & 20 \\
\hline$>60$ & 9 & 13.8 \\
\hline Total & 65 & 100 \\
\hline
\end{tabular}

Table-2: Age-wise distribution study participants; $\mathbf{n}(\%)$.

\begin{tabular}{|l|l|l|l|}
\hline \multicolumn{1}{|c|}{ Age } & \multicolumn{1}{c|}{ Benign } & \multicolumn{1}{c|}{ Malignant } & \multicolumn{1}{c|}{ Total } \\
\hline $31-40$ & $24(37)$ & $4(6)$ & $28(43.77)$ \\
\hline $41-50$ & $10(15.4)$ & $5(7.7)$ & $15(23.07)$ \\
\hline $51-60$ & $4(6.2)$ & $9(14)$ & $13(20)$ \\
\hline$>60$ & $2(3)$ & $7(11)$ & $9(13.8)$ \\
\hline Total & $40(62)$ & $25(38)$ & $65(100)$ \\
\hline
\end{tabular}

Out of the 65 (100\%) study participants, age wise, $43.7 \%$ (28) were included in $31-40$ years age group, $23.0 \%$ (15) in $41-50$ years group, $20 \%$ (9) in $51-60$ and $13.8 \%$ (9) were included in $>60$ years age group (Table 1 ).

In this study, $62 \%$ (40) and $38 \%$ (25) were diagnosed to be benign and malignant cases, respectively. Age-wise, 37\% (24) were benign cases in $31-40$ years group, $15.4 \%$ (10) in $41-50$ years group, $6.2 \%$ (4) in 51-60 years group and $3 \%$ (2) in $>60$ years age group. Whereas $6 \%$ (4) cases were malignant in 31-40 years group, $7.7 \%$ (5) in 41-50 years group, $14 \%$ (9) in 51-60 years group and $11 \%$ ( 7 ) in $>60$ years group (Table 2 ).

In this study, the left side presentation was diagnosed in 63\% (41) cases, right side in 34\% (22) cases, and both sides in 3\% (2). Totally $12.3 \%$ (8) women were nulliparous, out of which 2 had malignant lesions and the rest $(57 ; 81.7 \%)$ were multiparous. Statistically, there was no significant difference between parity and malignancy ( $P$ $>0.05)$.

\section{Discussion}

Breast malignancy is the leading cause of organspecific cancer, prevalent today. Any female though strong enough to bear any kind of pain and sorrow, fear of breast malignancy puts her down. With increasing incidence in women below the age of 40 years, early detection and management can be addressed by a planned approach and proper guidance can be given for the female initially. Around $95 \%$ of breast malignancies were diagnosed using a triple assessment.
The utility of mammograms in women aged $<35$ years was limited. Purasri $P$ et al. retrospectively assessed 603 patients with breast lumps using the quadruple test was reported to be better for the diagnosis of breast lump especially among women aged $<35$ years [17]. The clinical assessment gives a clue in the stage of the disease process. Family history, reproductive history, menstrual status, and marital history completely serve as a guide to come to a diagnosis.

They also help to order necessary investigations. The mean age among the patients with malignancy was 47 years, ranging between 30 to 65 years. This conforms with the suitable age for subjecting patients to screening procedures followed worldwide. The mean age was reported to be 49 years by Morris $A$ et al. [18], 48 years by Mande $N$ et al [19], 33.6 years by Ghafouri A et al. [20].

The maximum incidence of benign cases was noted in the third and fourth decade of life with decreasing incidence in premenopausal and postmenopausal age groups. The maximum incidence of malignant cases was noted in the sixth decade of life followed by the fourth decade; The later shows increasing incidence in women in spite of having given birth to the child. In this study, the most common symptom of the presentation was a lump in the breast followed by pain, discharge from the nipple, and trauma. Even in the literature also, the lump was reported to be the chief complaint $[21,22,23]$.

In this study, patients with pain in the breast and discharge nipple came to the hospital within 3 to 5 months of mean duration. The mean duration of the symptoms was reported as 1-3 months by Jaykar $\mathrm{R}$ D et al. [24], 6-12 months by Prajapati C L et al [23]. In this research, the left side lump was diagnosed in the majority $(63 \%)$ of the participants followed by right (34\%) and both (3\%) sides. However, the right side was reported by Masooda J $M$ et al. [21] and left side by Jaykar R D et al. [24], Prajapati C L et al. [23].

Three out of 65 patients had a positive history of breast complaints in the past. One patient had benign cystosarcoma phyllodes, which turned out to be malignant cystosarcoma. The other two were diagnosed as benign pathology earlier and even now had fibroadenoma in the same quadrant and the other patient had recurrent fibroadenomas. Seven patients out of 65 had a positive family history of breast and uterine malignancy, out of which 4 females were diagnosed with breast 
Malignancy and treated. Out of 65 cases in this study, 8 women did not have children due to various reasons and 57 women had children. Nulliparous women were reported to be 12 and 16, respectively in Masooda J M et al. [21] and Nigam M et al. [22] studies.

Out of 57 women who had children, only 53 patients had given breastfeeding to their children. 14 patients had complaints during the breastfeeding period, of which most of them had breast abscess during the first three months of the lactation period. The mean breastfeeding period in this study was 425 days. Whereas it was reported to be 528 days in Ghafouri A et al [20] study. Among 4 who are not given breastfeeding, two women had breast cancer. The relative risk of breast cancer decreased by 4.3\% (95\% CI 2.9-5.8; $P<0.0001$ ) for every 12 months of breastfeeding and by $3.4 \% \quad(0.9 \%$; $P<0.0001)$ for each child breastfed. The longer women breastfed, the more they were protected against breast cancer. The lack of breastfeeding or shorter duration of breastfeeding made a major contribution to the higher incidence of breast cancer in these countries.

Size of breast lump ranging from $3-12 \mathrm{~cm}$ was noted in the present study, only three patients had a lump size of more than $10 \mathrm{~cm}$, with the maximum incidence in the range of $4-7 \mathrm{~cm}$. The lump size was reported as 5-8 cm by Masooda J $M$ et al. [21] study.

The presence of a breast lump is the most common presenting and predictive symptom in women with breast cancer, while the incidence of breast cancer is consistently shown to be associated with increasing age [25]. Pathologic nipple discharge has also been associated with an increased incidence of breast cancer.

The UK prospectively study on 2064 patients referred to a breast unit over a 12-month period [26]. The authors reported that increasing age (OR $=1.08,95 \%$ CI 1.07-1.09, $P<0.001)$ and the presence of a discrete lump (OR $=5.08,95 \% \mathrm{CI}$ 3.07-8.4, $P<0.001$ ) were significant discriminatory predictors of breast cancer, in keeping with the findings of the present study. A later study also reported that increasing age, presence of a discrete lump, presence of a lump tethered to the skin or chest wall, a lump $\geq 2.0 \mathrm{~cm}$ in size, presence of breast thickening, lymphadenopathy all independently increased the probability of a woman having breast cancer [27].
In the present study, the sensitivity of clinical examination was $93 \%$, specificity of $100 \%$, PPV $93.02 \%$, and NPV of 93.33\%. Results were concordant with the previous studies $[18,28]$. Ultrasonogram was calculated to be $93 \% \%$, specificity $100 \%$, PPV $93.2 \%$ and NPV $93.33 \%$. Other studies analyzed the combined mammogram and ultrasonogram efficiency and reported that the techniques were $100 \%$ sensitive and $80.1 \%$ specific [29] diagnosis of palpable breast lumps.

In the present study, the sensitivity of pre-operative triple assessment was calculated to be $100 \%$ sensitive, specific and PPV was $100 \%$, NPV was $100 \%$. The same was compared with postoperative histopathology reports. This was concordant with available literature $[30,31]$.

\section{Limitations}

Small sample size is the major limitation of the study. Most of the study participants were from rural setup, hence the regional variation is another limitation of this report.

\section{Conclusion}

The anxious female with a lump in the breast can be accurately diagnosed and managed with a stratified approach like triple assessment. It gives a clear idea for diagnosis as well as to plan treatment. Among the three components of this triple assessment, FNAC is considered to be the most reliable component, especially in doubtful cases. Studies on large sample size, thorough and education regarding the self-breast examination. Awareness is to be created for the public through Anganwadi workers and midwives and by establishing breast clinic camps.

\section{What this study adds to existing knowledge}

Early diagnosis and staging of malignant diseases are possible with triple assessment especially in high-risk females including those with early or late menarche, usage of oral contraceptive pills, nulliparous women, and so on. FNAC is considered to be the most reliable component.

\section{Author's contributions}

Dr. G. Rajani Devi: Literature survey, Paper writing

Dr. Kallakuri Sailaja: Data analysis, Paper writing 


\section{Reference}

01. Sandhu DS, Sandhu S, Karwasra RK, Marwah S. Profile of breast cancer patients at a tertiary care hospital in north India. Indian $\mathrm{J}$ Cancer. 2010;47(1)16-22.

doi: 10.4103/0019-509X.58853 [Crossref]

02. Cochrane RA, Singhal H, Monypenny IJ, Webster DJ, Lyons K, Mansel RE. Evaluation of general practitionar referral to a specialist breast clinic according to the UK national guidelines. Eur J Surg Oncol. 1997;23(3)198-201.

doi: $10.1016 / s 0748-7983(97) 92220-4$ [Crossref]

03. Frykberg ER, Kirby BI. Evolution of surgical principles and techniques for the management of breast cancer, In- Kirby BI, Copeland EM. The breast -Comprehensive management of benign and malignant disease. Philadelphia- WB Saunders Company.

Vol- 2, 2nd ed,1998;766-801 [Crossref]

04. Klein S. Evaluation of a palpable breast mass. Am Fam Physician. 2005;71(9)1731-1738. [Crossref]

05. Donegan WL. Evaluation of a palpable breast mass. N Engl J Med. 1992;327(13)937-942.

doi: $10.1056 /$ NEJM199209243271307 [Crossref]

06. Johansen C. A clinical study with special reference to diagnostic procedures. Acta clin Scand. 1975;451(I)1-70.

doi: $10.1007 /$ BF01556840 [Crossref]

07. Hermansen C, Skovgaard Poulsen H, Jensen J. Diagnostic reliability of combined physical examination, mammography and fine needle puncture (triple test) in breast tumours- a prospective study. Cancer. 1987;60(8)18661868.

doi: $10.1002 / 1097-0142(19871015) 60: 8<1866$ : :aidcncr2820600832>3.0.co;2-z [Crossref]

08. Vetto JT, Pommier RF, Schmidt WA, Eppich $H$, Alexander PW. Diagnosis of palpable breast lesions in younger women by the modified triple test is accurate and cost-effective. Arch Surg. 1996;131(9)967-974.

[Crossref]
09. Vetto J. Use of the triple test for palpable breast lesion yields high diagnostic accuracy and cost savings. Am J Surg. 1995;169(5)519-522.

doi: $10.1016 /$ S0002-9610(99)80209-8 [Crossref]

10. Thomas JM, Fitzharris BM, Redding $W H$, Williams JE, Trott PA, Powles TJ, et al. Clinical examination, xeromammography, and fineneedle aspiration cytology in diagnosis of breast tumours. Bri Med J. 1978;2(6145)1139. doi: $10.1136 / \mathrm{bmj} .2 .6145 .1139$ [Crossref]

11. Dixon JM, Anderson TJ, Lamb J, Nixon SJ, Forrest APM. Fine-needle aspiration cytology in relationship to clinical examination and mammography in the diagnosis of a solid breast mass. Br J Surg. 1984;71(8)593-596.

doi: $10.1002 /$ bjs.1800710809 [Crossref]

12. Townsend Jr C, Beauchamp R, Evers B, Mattox K. Sabiston textbook of surgery. 19th edition, Philadelphia- Elsevier Saunders. 2012;826-834. [Crossref]

13. Eriko Tohno, David Ocosgrove, Jhon D S. Basic aspects and Diagnostic features on Ultrasound. Churchill Livingstone. 1994;3;49-74. [Crossref]

14. Wild JJ, Neal D. Use of high-frequency ultrasonic waves for detecting changes of texture in living tissues. Lancet. 1951;24(1)655-657.

doi: $10.1016 / s 0140-6736(51) 92403-8$ [Crossref]

15. Zuber M Naib. Exfoliative cytology, Boston, Little, Brown and Company. 1996;18;477-495. [Crossref]

16. Webb AJ. Early microscopy- history of fine needle aspiration (FNA) with particular reference to goitres. Cytopatology. 2001;12(1)1-7. doi: $10.1046 / j .1365-2303.2001 .00276 . x$ [Crossref]

17. Purasiri $P$, Abdalla $M$, Heys SD, Ah-See AK, McKean ME, et al. A novel diagnostic index for use in the breast clinic. J R Coll Surg Edinb. 1996;41(1)30-34.

[Crossref]

18. Morris A, Pommier R F, Morris K T. Usefulness of the triple test score for palpable breast masses. Arch Surg. 1998;136(9)1008-1013.

doi: 10.1001/archsurg.133.9.930 [Crossref] 
19. Mande M, Gakwaya AM, Byanyima RK. The triple assessment in the preoperative evaluation of patients with breast cancer in Mulago Hospital Kampala - Uganda. East Central Afr J Surg. 2004;9(2)111-116.

[Crossref]

20. Ghafouri A, Attarian SH, Tavanagar M, Sedighi N. Modified Triple test score for evaluation of palpable breast masses in women under age 40 . Med Jour Islam Repub Iran. 2006;20(3)115118.

[Crossref]

21. Jan M, Mattoo JA, Salroo NA, Ahangar S. Triple assessment in the diagnosis of breast cancer in kashmir. Ind J Surg. 2010;72(2)97-103.

doi: $\quad 10.1007 / \mathrm{s} 12262-010-0030-7 \quad$ [Crossref]

22. Manisha N, Brijender N. Triple assessment of breast - Gold standard in mass screening for breast cancer diagnosis. IOSR-JDMS. 2013;7(3)1-7.

[Crossref]

23. Jaykar RD, Kasbe P, Pargaonkar RP. A study of Modified Triple test score for assessment of palpable breast masses in young females. Int J Rec Trends Sci Techno. 2013;7(2)63-73.

doi: 10.1245/s10434-012-2710-y [Crossref]

24. Hatada T, Aoki I, Okada K. Usefulness of ultrasound-guided, fine-needle aspiration biopsy for palpable breast tumors. Arch Surg. 1996;131(10)1095-1098.

doi: $\quad$ 10.1001/archsurg.1996.01430220089020

[Crossref]

25. Beenken SW. History of the therapy of breast cancer- In Copeland BA, ed, The BreastComprehensive Management of Benign and Malignant Disorder. Philadelphia- Saunders. 2004; 5.

[Crossref]
26. Mohammed AZ, Edino ST, Ochicha O, Alhassan SU. Value of fine needle aspiration biopsy in preoperative diagnosis of palpable breast lumps in resource poor countries- A Nigerian experience. Ann Afric Med. 2005;4(1)19-22. Available at [Article] [Crossref]

27. Yang WT, Mok CO, King W, Tang, Metreweli C. Role of high frequency ultrasonography in the evaluation of palpable breast masses in Chinese women- Alternative to mammography. J Ultrasound Med. 1996;15(9)637-644. doi: $10.7863 /$ jum.1996.15.9.637 [Crossref]

28. Shetty MK, Shah YP, Sharman RS. Prospective evaluation of the value of combined mammographic and sonographic assessment in patients with palpable abnormalities. J Ultrasound Med. 2003;22(3)263-268. doi: $10.7863 /$ jum.2003.22.3.263 [Crossref]

29. Steinberg JL, Trudeau ME, Ryder DE, Fishell E, ChapmanJA, McCready DR, et al. Combined fine-needle aspiration, physical examination and mammography in the diagnosis of palpable breast masses- their relation to outcome for women with primarybreast cancer. Can J Surg. $1996 ; 39(4) 302-311$.

[Crossref]

30. Surati KN, Suthar KD, Parekh B, Shah JK. A study of accuracy of triple assessment as a clinical tool for the diagnosis of a palpable breast lump. Int J Med Sci Public Health. 2013;2(3)733-737.

doi: 10.5455/ijmsph.2013.070520134 [Crossref]

31. Prajapati CL, Jegoda RKK, Patel UA, Patel J. Breast lumps in a teaching hospital- A 5 year study. Nat J Med Res. 2014;4(1)65-67. [Crossref] 